\title{
Analysis on Current Practice and Needs based Survey of Parents and Speech-Language Pathologists for Reading Intervention with Smart Device Applications
}

\author{
Youngmee Lee ${ }^{\mathrm{a}}$, Young Tae Kim ${ }^{\mathrm{b}}$, Eun Hye Park \\ a Department of Communication Disorders, Tongmyong University, Busan, Korea \\ ${ }^{b}$ Department of Communication Disorders, Ewha Womans University, Seoul, Korea \\ 'Department of Special Education, Ewha Womans University, Seoul, Korea
}

\author{
Correspondence: Young Tae Kim, PhD \\ Department of Communication Disorders, \\ Ewha Womans University, 52 Ewhayeodae-gil, \\ Seodaemun-gu, Seoul 03760, Korea \\ Tel: $+82-2-3277-2120$ \\ Fax: +82-2-3277-2122 \\ E-mail: youngtae@ewha.ac.kr
}

Received: June 22, 2016

Revised: August 2, 2016

Accepted: August 8, 2016

This work was supported by the Ministry of Education of the Republic of Korea and the National Research Foundation of Korea (NRF2015S1A5A2A03049681)

\begin{abstract}
Objectives: The purpose of this study was to investigate the current practices, difficulties and needs of speech-language pathologists (SLPs) and parents in the reading intervention for children with reading difficulties and to make suggestions for developing smart device applications as reading intervention tools for them. Methods: Questionnaires were developed to examine the experience, difficulties, and needs in smart device applications regarding reading intervention. The survey was conducted in an online format, with a total of 120 questionnaires (60 SLPs, 60 parents) analyzed in the study. Results: SLPs had significantly more experience and difficulties than parents in intervention for children with reading difficulties. SLPs had significantly more support needs than parents when using smart device applications for intervention. Applications providing reading materials for intervention were highly desired by both SLPs and parents. Conclusion:The current study provides data showing that SLPs and parents have support needs when using reading intervention services via smart device applications for children with reading difficulties.
\end{abstract}

Keywords: Reading intervention, Children, Speech-language pathologists, Parents, Needs investigation, Reading intervention applications
스마트 기기는 네트워크 기능이 탑재되어 인터넷 접속이 가능하 며 OS 플랫폼을 통해서 제공되는 다양한 기능 및 서비스를 이용하 는 기기로 정의되며, 대표적으로 스마트폰, 태블릿 PC, 스마트 TV 가 여기에 속한다(Korea Information Society Development Institute, 2011). 스마트 기기는 이동통신사업과 정보통신사업의 발전과 함께 짧은 시간 안에 성능과 기능 측면에서 비약적으로 발전하였 다(Jang \& Kim, 2010). 스마트 기기는 단말기 자체보다는 단말기와 결합하는 콘텐츠에 따라서 이용 가치가 높아지는 특징을 지니고 있 어서, 사용자가 스마트 기기에 어플리케이션(application, 이하 앱) 을 설치함으로써 개인이 원하는 맞춤 콘텐츠를 인터넷 검색보다 쉽 고 빠르게 이용할 수 있다(Korea Information Society Development
Institute, 2011; Lee, Lee, \& Sung, 2015). 또한, 사용자는 앱을 통해 시공간 제약 없이 학습과 간접 경험의 기회를 가지며, 양방향 소통 으로 사용자 맞춤형의 콘텐츠를 갖추어서 사용할 수 있다(Lee \& Lee, 2014; Lee et al., 2015). 이러한 장점으로 인해 스마트 기기는 전 화 통화와 메시지를 주고받는 의사소통 기능에만 그치지 않고, 자 료 저장 및 전달, 학습, 여가 활동(음악, 게임), 쇼핑, 금융 등에 이르 기까지 우리의 일상생활 깊숙하게 영향을 미치고 있다(Korea Internet \& Security Agency, 2015). 교육과 의사소통 분야에서도 새 로운 형태의 앱이 계속해서 개발, 보급되고 있으며, 교육과학기술 부에서 2011년에 장애 학생을 위한 스마트 러닝 추진안을 발표하면 서 장애 학생을 위한 앱 개발과 배포에 대한 관심이 높아지고 있다 
(Lim \& Park, 2012). 현재 스마트 기기의 보급과 사용은 특정 연령 대와 계층에 국한되지 않고 우리 사회에 광범위하게 사용되고 있으 며, 다양한 앱을 활용하여 교육과 재활에서의 진단, 중재, 훈련을 지 원하는 스마트 러닝, 스마트 케어, 헬스케어 분야까지 확산되고 있다 (Jang \& Kim, 2010; Korea Internet \& Security Agency, 2015; Lee et al., 2015). 향후 스마트 기기와 앱은 우리의 일상생활에 더 많은 영 향을 미칠 것이며, 앱 콘텐츠의 중요성과 효용성은 더욱 대두될 것 으로 보여진다.

일반 아동은 초등학교 입학 전부터 읽기 선수기술을 학습하기 시작하여 큰 어려움이 없이 읽기 능력을 습득하지만, 의사소통장 애 아동의 상당수가 읽기 발달에 문제를 보이며 이로 인하여 학습 에도 어려움을 겪게 된다(Snow, Burns, \& Griffin, 1998). Baumeister, Campbell, Krueger, 그리고 Vohs (2003)는 읽기 능력이 다른 능 력을 갖추기 위한 대표적인 도구기술로 읽기에 문제를 지닌 학생은 학교 교육의 많은 영역에서도 문제를 가질 확률이 높기 때문에 조 기부터 중재를 해야 한다고 강조하였다. 읽기장애 아동은 일반 아 동에 비해 음소인식을 포함한 전반적인 음운처리 과정에서의 어려 움과 단기기억 과정에서의 효율적인 음성 부호화의 어려움으로 인 해 읽기재인에서 어려움을 보이며(Lee \& Park, 1999), 낱말재인을 위한 음운 처리 또는 직접 인출을 시도하는 과정에서 나타나는 오 류 때문에 일반 아동의 읽기 발달 양상과는 차이를 보인다고 보고 되었다(Kim, Choi, Jung, \& Kim, 2012). 또한, 청각장애 아동은 보 청기와 인공와우로 전달되는 청각정보만으로는 읽기 발달의 선수 기술인 음소 및 음절 인식, 음운인식, 음운정보의 발달에 어려움을 겪게 된다(Lee, 2015; Lee, Yim, \& Shim, 2012). 지적장애 아동은 제 한된 인지능력으로 인하여 읽기학습의 방식이 일반아동의 음운적 접근방식이 아닌 시각적 접근방법에 의존하여, 단어나 음절을 하 나의 단위로 인식하는 학습 수준에 머무르게 된다(Je, 2014). 읽기 에 어려움을 가진 학생은 자신의 능력에 대해 부정적인 견해를 가 지게 되고 학업에 흥미를 잃으며, 이러한 읽기 문제는 성인기까지 지속되어 취업과 사회생활에 중대한 영향을 미치게 된다(McNulty, 2003). 즉, 읽기 문제는 생애주기에 걸쳐 지속될 수 있기 때문에, 조기에 장애 학생의 읽기 특성에 맞는 집중적이고 효과적인 중재가 필요하다.

장애 아동을 위한 읽기 중재는 장애 및 읽기 문제의 특성 등을 고려하여 해독(decoding)과 독해(comprehension)의 두 가지 측면 을 충족시킬 수 있는 접근이 필요하다. 미국 국립아동건강 및 인간 개발협회(National Institute of Child Health and Human Development)에서는 조기 읽기 중재는 음소인식, 글자-음소의 관련성, 단 어-말소리 규칙, 단어의 발음에 대해서 직접적이고 체계적으로 가
르쳐야 하며, 글자-음소 관계를 이해할 수 있는 교재를 제공하고, 언어 이해를 돕기 위한 흥미로운 이야기를 활용하라고 명시하고 있 다(Grossen, 2003). 그리고 미국 언어청각협회(American SpeechLanguage-Hearing Association, ASHA)에서는 언어치료사의 역할 을 의사소통장애 판별, 진단, 사회적 의사소통 발달에 그치는 것이 아니라 아동기부터 청소년기까지의 학업 능력 증진 및 기타 기술을 습득하기 위한 읽기 능력 발달을 고려한 언어재활서비스 확장에 대 해서 언급하고 있다(Kamhi, Allen, \& Catts, 2001; Plumb \& Plexico, 2013). 하지만 국내에서는 장애 아동의 읽기 특성에 특화된 체계적 인 중재 프로그램이 부족하여, 일반 유아교육 자료를 활용하거나 일반교육이나 특수교육에서의 기본교육과정의 내용을 참고하는 수준에 머무르고 있다. 현장에서 교사는 다른 교과에 비해 국어 교 과에서 의사소통장애 아동의 수업 진행에 어려움을 크게 느끼고 있으며, 언어치료사도 장애 아동을 위한 읽기 중재의 필요성에 대 해서는 인식하고 있으나 읽기 발달 수준에 따른 다양한 접근을 시 도하는 데 어려움을 가지고 있다(Lee, 2014; Park, 2013).

최근 장애 아동의 기능적 읽기의 중요성이 강조되면서 체계적인 읽기 중재, 기초 단계를 강화한 읽기 중재, 대안적 상징을 이용한 읽 기 중재 등이 필요하다는 인식이 높아졌지만, 국내에는 장애 아동 을 위한 읽기 접근을 비롯한 관련 중재에 대한 연구가 매우 부족하 다. 선행 연구(Campbell \& Mechling, 2009; Lonigan et al., 2003; Macaruso, Hook, \& McCabe, 2006)에서는 컴퓨터를 이용한 중재 (computer-assisted instruction)가 장애 아동의 읽기 기술을 가르 치는데 효과성과 효율성이 높은 방법이며, 장애 아동에게 읽기 기 술을 습득하기 위한 보다 많은 연습 기회를 제공, 아동의 반응에 대 한 즉각적인 피드백과 강화, 흥미 유발 등과 같은 긍정적인 효과에 대해서 보고하였다. 또한, 읽기 중재의 효율성을 증진시키기 위해 서 개발된 스마트 기기에서의 앱이나 소프트웨어를 활용하는 것은 장애 아동의 동기 유발, 체계성, 교수의 용이성, 장애 낙인 감소 등 의 효과를 보이는 것으로 보고되고 있다(Ahlgrim-Delzell et al., 2016; Chai, Ayres, \& Vail, 2016; Chai, Vail, \& Ayres, 2015; De Leo, Gonzales, Battagiri, \& Leroy, 2011). Chai 등(2015)이 초기 문해능 력 향상을 목적으로 개발한 앱을 5 세부터 8 세의 장애 아동 $(\mathrm{N}=3)$ 에게 $\mathrm{iPad}$ 를 이용하여 읽기 중재를 실시한 결과, $\mathrm{iPad}$ 상에서 어두 초성 음소를 이해하는 능력이 향상되었으며, 습득한 음소 이해 능 력은 다른 자료에서의 일반화와 중재 후 유지도 가능하였다. 스마 트 기기의 앱을 이용한 중재는 기존의 컴퓨터를 이용한 중재의 긍 정적인 효과는 그대로 유지하되 스마트 기기의 휴대성과 편의성으 로 인한 장애 아동의 중재 접근성을 높여주며, 장애 아동의 직접 조 작을 통한 앱과 상호작용을 함으로 인해서 중재 동안 흥미를 유지 
할 수 있는 것이다(Ahlgrim-Delzell et al., 2016; Chai et al., 2016).

스마트 기기가 광범위하게 보급됨에 따라 장애 아동도 의사소통 기회 및 기술의 향상, 학습 참여 등의 이유로 언어병리학과 특수교 육 분야에서도 스마트 기기를 이용하는 다양한 매체 활용에 대한 관심이 높아지고 있다. 정보통신기술의 발달과 함께 장애 아동의 의사소통과 교육에서도 휴대성, 보편성, 편재성을 지닌 교육 콘텐 츠의 개발이 중시되고 있으며, 과거의 소프트웨어 프로그램 개발에 서 스마트 기기 기반의 앱 개발로 변화되고 있다. 이러한 시점에서 전문가가 개발한 읽기 중재 콘텐츠가 스마트 기기 기반의 앱으로 개발되어 배포된다면, 교육 현장과 가정에서 장애 아동의 읽기 중 재에 효율적으로 사용될 수 있을 것이다. 언어병리학과 특수교육 분야에서 다양한 매체를 활용하는 중재 전략과 방법에 대해서 연 구를 하고 있지만 빠른 속도로 발전하고 있는 스마트 기기 및 프로 그램을 활용하기 위한 기초 자료가 부족한 상황이다. 장애 아동에 게 도움이 되는 읽기 중재 콘텐츠를 개발하기 위해서는 전문가와 부모가 장애 아동의 읽기 중재에서 지니는 어려움을 파악하고, 전 문가와 장애 아동의 가족들이 필요로 하는 읽기 중재 콘텐츠에 대 한 요구 파악이 선행되어야 한다.

본 연구는 장애 아동의 부모와 언어치료사의 읽기 중재 경험과 어려움에 대해서 살펴보고, 장애 아동의 읽기 수행력 향상을 위해 서 필요한 스마트 기기의 앱 콘텐츠의 유형과 요구도를 조사하고자 하였다. 이를 통해서 장애 아동의 읽기 중재에도 스마트 러닝의 도 입 가능성을 모색하고, 교육 현장과 가정에서 필요로 하는 실제적 인 읽기 중재 앱을 개발하는 기초자료로 활용되고자 한다. 구체적 인 연구 질문은 다음과 같다.

첫째, 언어치료사와 부모의 장애 아동에 대한 읽기 중재 경험은 어떠한가?

둘째, 집단(언어치료사, 부모)과 읽기 교수 요인(학습환경, 교과 내용 및 평가, 교수방법)에 따른 장애 아동의 읽기 중재 어려움에 유의한 차이가 있는가?

셋째, 집단(언어치료사, 부모)에 따른 장애 아동의 읽기 중재 관 련 앱 콘텐츠 유형에 유의한 차이가 있는가?

\section{연구방법}

\section{연구대상}

본 연구는 언어치료사와 언어치료를 받고 있는 장애 아동의 부 모를 대상으로 하였으며, 연구 참여자의 정보는 Table 1 에 제시하였 다. 분산분석을 위한 대상자 수를 파악하기 위해서 $\mathrm{G}^{\star}$ Power 프로 그램(Faul, Erdfelder, Buchner, \& Lang, 2009)을 이용하여 검증력
Table 1. Participants' characteristics

\begin{tabular}{|c|c|c|}
\hline Classification & Characteristic & Frequency (\%) \\
\hline \multirow{19}{*}{$\operatorname{SLPS}(N=60)$} & Sex & \\
\hline & Male & $1(1.7)$ \\
\hline & Female & $59(98.3)$ \\
\hline & Certification & \\
\hline & 1st grade SLP & $31(51.7)$ \\
\hline & 2nd grade SLP & $29(48.3)$ \\
\hline & Place of workplace & \\
\hline & Seoul & 38 (63.3) \\
\hline & Incheon & $1(1.7)$ \\
\hline & Daejeon & $6(10.0)$ \\
\hline & Gwangju & $2(3.3)$ \\
\hline & Busan & $13(21.7)$ \\
\hline & Career (yr) & \\
\hline & $<1$ & $4(6.7)$ \\
\hline & $1-3$ & $16(26.7)$ \\
\hline & $3-5$ & $9(15.0)$ \\
\hline & $5-7$ & $9(15.0)$ \\
\hline & $7-9$ & $4(6.7)$ \\
\hline & $\geq 9$ & $18(30.0)$ \\
\hline \multirow[t]{28}{*}{ Parents $(\mathrm{N}=60)$} & Relationship to child & \\
\hline & Father & $5(8.3)$ \\
\hline & Mother & $53(88.3)$ \\
\hline & Others & $2(3.4)$ \\
\hline & Parents' age (yr) & \\
\hline & $<30$ & $0(0)$ \\
\hline & $30-34$ & $1(1.7)$ \\
\hline & $35-39$ & $26(43.3)$ \\
\hline & $\geq 40$ & $33(55.0)$ \\
\hline & Sex of a child & \\
\hline & Male & $37(61.7)$ \\
\hline & Female & $23(38.3)$ \\
\hline & Age of a child (yr) & \\
\hline & $3-5$ & $11(18.3)$ \\
\hline & $5-8$ & $29(48.3)$ \\
\hline & $8-10$ & $11(18.3)$ \\
\hline & $\geq 10$ & $9(15.0)$ \\
\hline & Type of disability & \\
\hline & ID & $11(15.7)$ \\
\hline & $\mathrm{PD} / \mathrm{CP}$ & $0(0)$ \\
\hline & $\mathrm{RD}$ & $3(4.3)$ \\
\hline & ASD & $16(22.9)$ \\
\hline & ADHD & $1(1.4)$ \\
\hline & $\mathrm{HI}$ & $18(25.7)$ \\
\hline & FD & $1(1.4)$ \\
\hline & SSD & $4(5.7)$ \\
\hline & SLI & $2(2.0)$ \\
\hline & LD & $14(20.0)$ \\
\hline
\end{tabular}

$\mathrm{SLP}=$ speech-language pathologist; $I \mathrm{D}=$ intellectual disability; $\mathrm{PD} / \mathrm{CP}=$ physical disability or cerebral palsy; $\mathrm{RD}=$ reading disability; $\mathrm{ASD}=$ autism spectrum disorder; $\mathrm{ADHD}=$ attention deficit/hyperactivity disorder; $\mathrm{HI}=$ hearing impairment; $\mathrm{FD}$ = fluency disorder; $S S D=$ speech sound disorder; $S L I=$ specific language impairment; $L D=$ learning disability. 
.80 , 유의수준 .05 (양측검증), 효과크기 .30으로 산출한 결과, 집단 별로 43 명 이상의 대상자가 필요한 것으로 나타났다. 불성실한 응 답 및 미응답 등을 고려하여 집단별로 최소 60 명 이상의 대상자에 게 설문을 진행하고자 하였다. 본 연구에서는 총 126 명(언어치료사 64 명, 부모 62 명)이 온라인 설문에 응답하였으며, 중복 응답 및 불 충분하게 작성된 설문지를 제외하여 총 120 부(95.2\%)의 설문지만 을 분석하였다. 요건이 충족된 연구 대상자는 언어치료사 60 명, 장 애 아동의 부모 60 명이었다. 두 집단 모두 응답자의 여성 비율이 남 성에 비해서 높았으며, 집단별 여성의 비율은 언어치료사 $98.3 \%$, 부 모 $91.7 \%$ 였다. 기술통계 결과, 언어치료사의 연령대는 30 대가 $45.0 \%$ 로 다른 연령대에 비해서 가장 높았으며, 임상 경력은 10 년 이상 된 경우가 $30.0 \%$ 로 가장 많았다. 언어치료사 중에서 1 급 언어치료사 는 $51.7 \%, 2$ 급 언어치료사는 $48.3 \%$ 였다. 장애 아동의 평균 연령은 7.48 세 $(\mathrm{SD}=3.23)$ 였으며, 장애 아동의 성별은 남아가 $53.3 \%$, 여아 가 $38.3 \%$ 였다. 장애 유형은 청각장애(25.7\%)가 가장 많았으며, 자폐 스펙트럼장애(22.9\%), 언어발달장애(20.0\%), 지적장애(15.7\%) 순으 로 나타났다.

\section{연구도구}

본 연구에서는 언어치료사와 장애 아동 부모의 읽기 중재의 실 태와 필요로 하는 앱 콘텐츠 유형을 살펴보기 위해서 설문지를 개 발하였다. 선행연구(Ganske, Monroe, \& Strickland, 2003; Grossen, 2003; Kang, Choi, \& Huh, 2007; Kim et al., 2012; Lee, 2014; Lee, Kang, \& Kim, 2013; Lee et al., 2015; Lerner, 2003)에서 언급하 고 있는 장애 아동의 읽기 중재 교수 전략, 교수-학습 요인, 읽기 중 재 영역, 콘텐츠 유형을 참고로 하여 1 차로 개발한 설문지를 언어병 리학과 교수 1 인과 특수교육학과 교수 1 인에게 내용의 타당성과 문 항의 적절성에 관해서 검증을 받아 설문지를 수정하였다. 그리고 언어치료사 3 인과 장애 아동의 어머니 3 인에게 수정된 설문지를 사 전 검사하여 용어, 문장 명료도, 문항 제시 순서 등의 보완을 거쳐 서 최종 설문지를 완성하였다.

설문지는 각각 (1) 읽기 중재 경험(공통 15 문항; 부모용 15 문항, 언어치료사용 16문항), (2) 읽기 중재 어려움(15문항), (3) 읽기 수행 력 향상을 위한 스마트 기기의 앱 콘텐츠 요구도(24문항), (4) 연구 참여자의 배경 정보(부모용 12 문항, 언어치료사용 10 문항)를 묻는 네 영역으로 구성하여, 장애 아동의 부모는 총 66 문항, 언어치료사 는 총 65 문항에 응답하도록 하였다. 읽기 중재 경험에서는 읽기 중 재를 한 장애 유형, 읽기 중재 목표 및 자료, 단어 인식, 읽기 유창성, 읽기 이해, 멀티미디어 사용 경험에 관한 문항을 구성하였다. 읽기 중재 어려움에는 읽기 중재 시의 학습환경, 교과 내용 및 평가, 교수
방법의 어려움에 관한 문항을 구성하였으며, 읽기 수행력 향상을 위한 앱 콘텐츠 요구도에는 읽기 수행력의 평가 및 모니터, 읽기 자 료 제시, 교수 및 반복 학습, 읽기 중재에 관한 정보를 제공하는 기 능의 앱에 대한 요구도를 묻는 문항이 포함되었다. 설문 문항은 주 로 선다형과 5점 척도로 응답하도록 개발하여, 읽기 중재 경험에 관한 문항은 '전혀 실시하고 있지 않다'부터 '중점적으로 실시하고 있다’까지, 읽기 중재 어려움에 관한 문항은 '전혀 그렇지 않다'부터 '매우 그렇다'까지, 앱 콘텐츠 요구도에 관한 문항은 '전혀 필요없다' 부터 '매우 필요하다'까지 5점 척도를 이용하여 응답하도록 하였 다. 그리고 부모와 언어치료사의 장애 아동에 대한 읽기 중재 경험 과 앱 사용 경험에 대한 실제 상황과 의견을 충분히 조사하기 위해 서 일부 문항에 대해서는 복수 응답이 가능하도록 하였다. 또한, 장 애 아동의 읽기 중재에 필요한 콘텐츠 유형에 대해서는 단일 응답 뿐만 아니라 기술형 응답도 가능하도록 하였다. 문항 내적 일관성 을 Cronbach's alpha 계수를 산출하여 분석한 결과 .931로 나타나 서 문항 간 내적 신뢰도가 높은 것으로 나타났다. 본 연구에서 사용 된 설문지 문항의 일부를 Appendix 1에 제시하였다.

\section{연구절차}

본 설문조사 기간은 2016년 2월 25일부터 3월 30일까지 실시하 였으며, 서울 및 경기, 인천, 대전, 부산 소재 기관에 연구 협조문을 이메일로 발송을 하고, 해당 기관의 담당자, 언어치료사에게 전화 및 구두로 연구의 목적과 내용에 대해서 설명하였다. 대부분의 설 문조사가 조사방법상 다양한 계층을 대상으로 조사하기에는 한계 가 있다는 것을 고려하여 구글닥스(Google Docs)를 활용하여 온 라인 설문지를 개발하였고, 이를 설문조사를 약속한 기관의 연구 참여자에게 이메일과 SNS를 활용하여 설문조사 참여를 위한 URL 주소를 배포하였다. 이때, 대상자는 연구 안내문을 숙지하고 연구 참여 동의를 한 후 온라인 설문조사에 참여하게 되었다. 장애 아동 의 부모는 연구에 참여하는 언어치료사의 소개로 연구의 취지를 듣고 설문 참여에 동의를 한 경우, 언어치료사나 연구자가 태블릿 $\mathrm{PC}$ 를 사용하여 부모가 온라인 설문조사에 참여하도록 하였다. 온 라인 설문조사에 참여한 총 126 부 중에서 중복 응답과 불성실한 응답을 제외한 120 부의 유효 표본을 통계분석에 사용하였다.

\section{자료처리}

본 연구에서 수집된 자료는 IBM SPSS Statistics version 22 (IBM, Armonk, NY, USA)를 사용하여 분석하였다. 대상자의 기본 정보 및 설문 문항에 대한 응답에 대해서 빈도와 백분율을 함께 산출하 였으며, 응답 차이를 분석하기 위하여 카이 제곱(chi-square) 검정 
Youngmee Lee, et al. • Needs in Smart Device Applications for Reading Intervention

과 분산분석(ANOVA)을 실시하였다. 복수 응답을 허용한 경우에 는 케이스백분율을 산출하였다.

\section{연구결과}

\section{언어치료사와 장애 아동 부모의 읽기 중재 경험}

언어치료사와 부모에게 장애 아동에게 읽기 중재의 실시 여부를 조사한 결과, 두 집단 모두 읽기 중재를 실시한 적이 있다고 응답하 였다. 언어치료사가 읽기 중재를 실시하는 장애 유형, 읽기 중재 목 표, 읽기 자료에 대해서 복수 응답을 허용하여 조사를 진행하였다. 언어치료사가 읽기중재를 실시한 장애 유형을 살펴보면, 지적장애 (22.0\%), 언어발달장애(17.2\%), 주의집중 및 과다행동장애(13.8\%), 읽기장애(11.0\%) 등의 순서로 나타났다(Table 2). 읽기 중재 목표의 경우, 언어치료사는 음운인식(18.4\%), 문장 읽고 이해하기(16.7\%), 어휘 읽고 이해하기(15.4\%), 문단 읽고 이해하기(14.0\%) 등의 순서 로, 부모는 어휘 이해하기(23.4\%), 단어 읽기(18.8\%), 한글 철자 익히

Table 2. Types of disabilities of children who received the reading instruction by speech-language pathologists

\begin{tabular}{lc}
\hline Classification & Frequency (\%) \\
\hline ID & $46(22.0)$ \\
PD/CP & $4(1.9)$ \\
RD & $23(11.0)$ \\
ASD & $17(8.1)$ \\
ADHD & $28(13.4)$ \\
HI & $15(7.2)$ \\
FD & $9(4.3)$ \\
SSD & $21(10.0)$ \\
SLI & $10(4.8)$ \\
LD & $36(17.2)$ \\
\hline
\end{tabular}

$\mathrm{ID}=$ intellectual disability; $\mathrm{PD} / \mathrm{CP}=$ physical disability or cerebral palsy; $\mathrm{RD}=$ reading disability; $A S D=$ autism spectrum disorder; $A D H D=$ attention deficit/hyperactivity disorder; $\mathrm{HI}=$ hearing impairment; $\mathrm{FD}=$ fluency disorder; $S \mathrm{SD}=$ speech sound disorder; $S L I=$ specific language impairment; $L D=$ learning disability.

Table 3. Frequency (\%) of goals for improving reading skills

\begin{tabular}{lcl}
\hline & SLPS & Parents \\
\hline Identifying Korean letters & $26(11.4)$ & $21(16.4)$ \\
Improving phonological awareness skills & $42(18.4)$ & $11(8.6)$ \\
Reading whole words & $23(10.1)$ & $24(18.8)$ \\
Reading sentences fluently & $32(14.0)$ & $15(11.7)$ \\
Increasing listening and speaking vocabulary & $35(15.4)$ & $30(23.4)$ \\
Understanding messages at the sentence level & $38(16.7)$ & $20(15.6)$ \\
Understanding messages at the paragraph level & $32(14.0)$ & $7(5.5)$ \\
\hline
\end{tabular}

$\mathrm{SLP}=$ speech-language pathologist.
기(16.4\%) 등의 순서로 나타났다(Table 3). 읽기 자료의 경우, 언어 치료사는 그림책 및 동화책(17.8\%), 직접 제작 자료(1.1\%), 그림 및 글자카드(11.6\%) 순서로, 부모는 그림책 및 동화책(32.7\%), 그림 및 글자카드(21.2\%), 일반 학습지(15.4\%) 순서로 나타났다(Table 4).

지도전략(단어재인, 읽기 유창성, 읽기 이해력, 멀티미디어 활용) 에 따른 언어치료사와 부모의 장애 아동에 대한 읽기 중재 경험에 대한 정보는 Figure 1과 같다. 언어치료사의 읽기 중재 경험은 단어 재인 $(\mathrm{M}=3.26, \mathrm{SD}=.65)$, 읽기 이해력 $(\mathrm{M}=3.19, \mathrm{SD}=.75)$, 읽기 유창 성 $(\mathrm{M}=2.33, \mathrm{SD}=0)$, 멀티미디어 활용 $(\mathrm{M}=2.03, \mathrm{SD}=.98)$ 순으로 나타났으며, 부모의 읽기 중재 경험은 단어재인 $(\mathrm{M}=2.99, \mathrm{SD}=.91)$, 읽기 유창성 $(\mathrm{M}=2.33, \mathrm{SD}=0)$, 읽기 이해력 $(\mathrm{M}=2.31, \mathrm{SD}=.97)$, 멀 티미디어 활용 $(\mathrm{M}=2.08, \mathrm{SD}=.99)$ 의 순으로 나타났다.

구형성 가정을 검정한 결과, 동질성 가정이 위배되는 것으로 나타

Table 4. Frequency (\%) of reading materials

\begin{tabular}{lcc}
\hline & SLPS & Parents \\
\hline Home-school materials & $24(9.3)$ & $24(15.4)$ \\
Picture/letter cards & $30(11.6)$ & $33(21.2)$ \\
Books & $46(17.8)$ & $51(32.7)$ \\
Textbook & $29(11.2)$ & $8(5.1)$ \\
Internet/Web & $27(10.4)$ & $0(0)$ \\
Board games & $22(8.5)$ & $0(0)$ \\
Hand-made materials & $39(15.1)$ & $11(7.1)$ \\
Computer based program & $5(1.9)$ & $1(0.6)$ \\
Applications & $8(3.1)$ & $9(5.8)$ \\
Visual and auditory materials & $9(3.5)$ & $0(0)$ \\
Logos and letters of life & $17(6.6)$ & $9(5.8)$ \\
Others & $3(1.2)$ & $10(6.4)$ \\
\hline
\end{tabular}

$\mathrm{SLP}=$ speech-language pathologist.

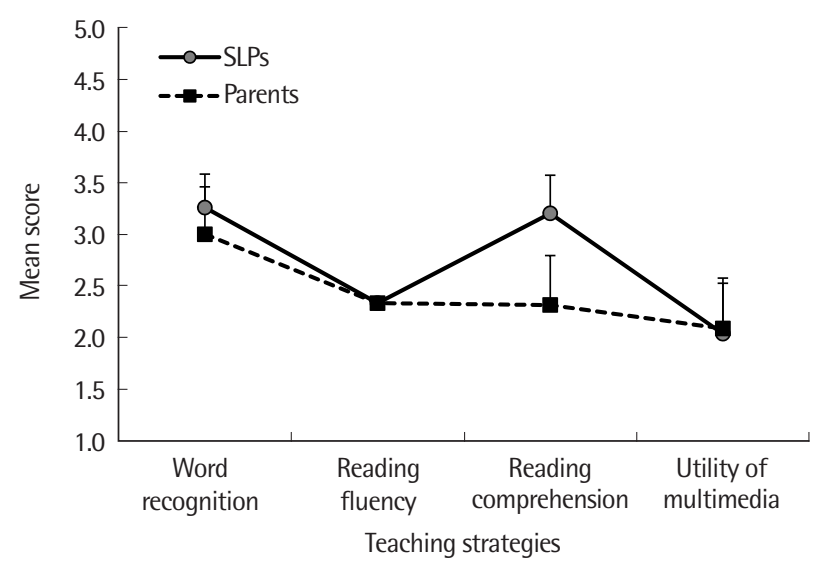

Figure 1. Comparative experience of reading intervention for children with special needs between speech-language pathologists (SLPS) and parents (fivepoint scale with a maximum score of 5). 
나서(Maunchly's W=.887, $\left.\chi^{2}=13.986, p<.05\right)$, Greenhouse-Geis$\mathrm{ser}$ 의 $F$ 값을 기초로 하여 해석하였다. 지도전략에 따른 집단 간 읽 기 중재 경험에 차이가 있는지 살펴보기 위해서 이원혼합분산분석 을 실시하였다. 그 결과, 집단에 대한 주효과가 유의하게 나타나서 $\left(F_{(1,118)}=9.052, p<.01\right)$, 언어치료사가 부모에 비해서 장애 아동의 읽기 중재에 더 많은 경험이 있는 것으로 나타났다. 지도전략에 따 른 주효과도 유의하여 $\left(F_{(2.803,118)}=58.028, p<.001\right)$, 이에 대해 Bonferroni 사후검정을 실시하였다. 그 결과, 모든 지도전략 간에 유의 한 차이가 나타났으며(all $p<.05)$, 단어재인, 읽기 이해력, 읽기 유 창성, 멀티미디어 활용 순으로 유의하게 낮아지고 있었다. 또한, 이 차 상호작용 효과가 유의하게 나타나서 $\left(F_{(2.803,118)}=12.201, p<.001\right)$, 이에 대한 사후검정으로 MMATRIX와 LMATRIX를 사용한 상호 작용 대비검정을 실시하였다. 그 결과, 읽기 이해력에서의 집단 간 의 중재 경험 차이가 단어재인, 읽기 유창성, 멀티미디어 활용에서 의 집단 간 차이보다 유의하게 컸다 $\left(F_{(1,118)}=31.335, p<.001\right)$. 즉, 이 차 상호작용 효과는 언어치료사가 부모에 비해서 장애 아동의 읽 기 중재에서 단어재인, 읽기 유창성, 멀티미디어 활용보다 읽기 이 해력 향상에 초점을 맞춘 중재 경험이 더 많은 것에서 기인한 것으 로 보여진다(Figure 1).

\section{읽기 중재 교수 요인에 따른 언어치료사와 장애 아동 부모 간의 읽기 중재의 어려움}

교수 요인(학습환경, 교과내용 및 평가, 교수방법)에 따른 언어치 료사와장애 아동의 부모의 읽기 중재 어려움을 조사한 결과는 Figure 2 와 같다. 언어치료사는 교수방법 $(\mathrm{M}=4.05, \mathrm{SD}=.25)$, 교과내용 및 평가 $(\mathrm{M}=3.98, \mathrm{SD}=.30)$, 학습환경 $(\mathrm{M}=3.30, \mathrm{SD}=.36)$ 순으로,

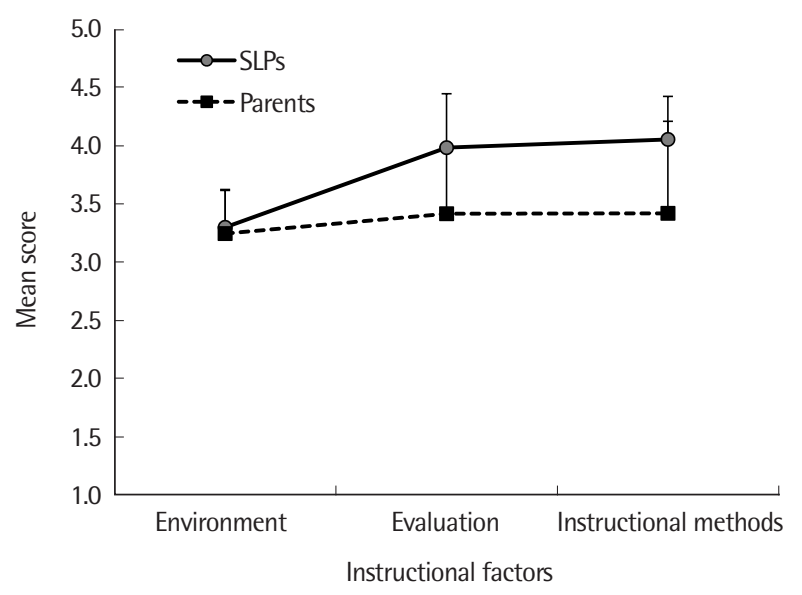

Figure 2. Comparative difficulties in reading intervention between speechlanguage pathologists (SLPS) and parents (five-point scale with a maximum score of 5).
부모도 교수방법 $(\mathrm{M}=3.42, \mathrm{SD}=.79)$, 교과내용 및 평가 $(\mathrm{M}=3.41$, $\mathrm{SD}=1.03)$, 학습환경 $(\mathrm{M}=3.24, \mathrm{SD}=.37)$ 순으로 읽기 중재에 어려 움을 지니는 것으로 나타났다.

구형성 가정을 검정한 결과, 동질성 가정이 위배되는 것으로 나 타나서(Maunchly's W=.831, $\chi^{2}=21.607, p<.001$ ), GreenhouseGeisser의 $F$ 값을 기초로 하여 해석하였다. 교수 요인에 따른 집단 간 읽기 중재 어려움에 차이가 있는지 살펴보기 위해서 이원혼합 분산분석을 실시하였다. 그 결과, 집단에 대한 주효과가 유의하여 $\left(F_{(1,118)}=8.835, p<.01\right)$, 언어치료사가 부모에 비해서 읽기 중재에 더 많은 어려움을 인식하고 있었다. 교수 요인에 대한 주효과도 유 의하게 나타나서 $\left(F_{(1.711,201.947)}=6.547, p<.01\right)$, 이에 대해 Bonferroni 사후검정을 실시하였다. 그 결과, 학습환경과 교과내용 및 평가 $(p<.01)$, 학습환경과 교수방법 $(p<.01)$ 간에 유의한 차이를 보여서, 장애 아동의 읽기 중재 시에 학습환경보다는 교과내용 및 평가와 교수방법에서 지각하는 어려움이 더 큰 것으로 나타났다(Figure 2).

\section{언어치료사와 장애 아동 부모 간의 읽기 중재 앱 콘텐츠 요구도}

장애 아동의 읽기 중재를 위한 앱 사용 경험을 묻는 질문에 언어 치료사는 $18.3 \%$ (11/60), 부모는 66.7\% (40/60)가 '있다'라고 응답해 서, 부모가 언어치료사보다 장애 아동의 읽기 중재를 위해서 앱을 사용해본 경험이 유의하게 더 많은 것으로 나타났다 $\left(\chi^{2}(1)=28.678\right.$, $p<.001)$. 읽기 중재에 앱을 사용해본 경험이 있는 응답자에게 앱 사 용 경로에 대해서 조사한 결과, 언어치료사는 전문가(81.7\%), 책 (18.3\%) 순서로, 부모는 책(66.7\%), 전문가(33.3\%) 순서로 나타나서, 집단 간에 앱을 이용하게 된 경로가 유의한 차이를 보였다 $\left(\chi^{2}(1)=\right.$ $28.678, p<.001)$. 앱 사용 경험자에게 읽기 중재에 사용한 앱 유형에 대해서 질문한 결과(복수 응답 허용), 언어치료사는 동화 구연(10\%), 한글 철자 익히기(20\%), 단어 익히기(20\%), 상징 그림판(20\%), 소리와 글자 매칭 $(20 \%)$, 독해(10\%) 관련 앱을, 부모는 동화 구연(30\%), 한글 철자 익히기(20\%), 단어 익히기(20\%), 소리와 글자 매칭( $15 \%)$, 상징 그림판(10\%), 독해(5\%) 관련 앱을 중재에 사용해본 경험이 있었다.

장애 아동의 읽기 중재를 지원할 수 있는 앱 콘텐츠에 대한 집단 의 요구를 알아본 결과는 Table 5에 제시하였다. 전체적으로는 '읽 기 수행력를 평가할 수 있는 콘텐츠, '다양한 난이도와 주제의 읽 기 자료를 제공하는 콘텐츠, '읽기 자료와 관련된 배경지식을 제공 하는 콘텐츠', ‘단어 읽기를 훈련할 수 있는 콘텐츠’에 대한 요구가 높게 나타났다. 그리고 '읽기 이해력 증진을 위한 문제 은행 형태의 콘텐츠’의 경우, 두 집단 간의 요구도에 유의한 차이가 있는 것으로 나타나서 $\left(\chi^{2}(1)=28.670, p<.001\right)$, 언어치료사가 '문장, 문단에 대한 이해를 높이기 위한 문제를 제공하는 앱 콘텐츠에 대한 요구가 부 
Youngmee Lee, et al. • Needs in Smart Device Applications for Reading Intervention

Table 5. Comparative needs for smart device application features for children with reading difficulties between SLPs and parents

\begin{tabular}{lcc}
\hline Needs in smart device applications & SLPS & Parents \\
\hline Evaluation of reading performance & $4.30(.79)$ & $3.87(.91)$ \\
Monitoring of children's reading performance & $4.27(.79)$ & $3.83(.92)$ \\
Feedback of children's response (performance) & $4.00(.90)$ & $3.98(.95)$ \\
Reading materials & $4.52(.70)$ & $4.12(.94)$ \\
Orally story-telling & $3.95(.96)$ & $4.12(.87)$ \\
Background information (e.g., pictures, videos) & $4.18(.89)$ & $4.07(.97)$ \\
Korean letters & $4.08(.83)$ & $3.80(1.13)$ \\
Logo, symbols, pictures & $3.90(.89)$ & $3.92(.99)$ \\
Word reading & $4.21(.76)$ & $3.93(1.09)$ \\
Phonological awareness & $4.33(.73)$ & $3.95(1.05)$ \\
Reading fluency & $4.05(.79)$ & $3.93(.99)$ \\
Learning vocabulary & $4.25(.73)$ & $4.08(.94)$ \\
Workbook for improving reading comprehension & $4.33(.73)$ & $3.78(.98)$ \\
Text to speech synthesis & $3.82(.95)$ & $4.00(1.03)$ \\
Sharing of children's information between SLPs and parents & $3.98(.85)$ & $4.07(.94)$ \\
Experience book to build reading skills & $4.27(.82)$ & $3.90(.95)$ \\
Lectures from professionals & $3.93(.89)$ & $3.82(.98)$ \\
Parental education about reading intervention & $4.12(.83)$ & $3.87(.91)$ \\
Materials about reading strategies and/or techniques & $4.05(.99)$ & $3.88(.88)$
\end{tabular}

Values are presented as mean (SD). Five-point scale with a maximum score of 5 . $\mathrm{SLP}=$ speech-language pathologist.

모에 비해서 높았다.

읽기 중재 앱의 콘텐츠 유형을 ‘평가 및 모니터링', '자료 제공', '반 복 학습' '정보 제공 및 공유'로 네 가지로 나누어서, 장애 아동의 읽 기 중재 콘텐츠에 대해 집단 간 요구에 차이가 있는지 살펴보았다 (Figure 3). 언어치료사는 자료 제공 $(\mathrm{M}=4.26, \mathrm{SD}=.66)$, 평가 및 모 니터링 $(\mathrm{M}=4.25, \mathrm{SD}=.65)$, 반복 학습 $(\mathrm{M}=4.16, \mathrm{SD}=.54)$, 정보 제 공 및 공유 $(\mathrm{M}=4.07, \mathrm{SD}=.69)$ 순으로, 부모는 자료 제공 $(\mathrm{M}=4.03$, $\mathrm{SD}=.85)$, 반복학습 $(\mathrm{M}=3.88, \mathrm{SD}=.89)$, 정보 제공 및 공유 $(\mathrm{M}=3.88$, $\mathrm{SD}=.82)$, 평가 및 모니터링 $(\mathrm{M}=3.86, \mathrm{SD}=.88)$ 순으로 요구도가 나 타났다(Figure 3).

읽기 중재 콘텐츠 유형에 따른 집단 간 차이가 있는지 살펴보기 위해서 이원혼합분산분석을 실시한 결과, 집단에 대한 주효과가 유의하게 나타나서 $\left(F_{(1,118)}=4.747, p<.05\right)$, 언어치료사가 부모에 비 해서 읽기 중재 콘텐츠 개발에 대한 요구도가 높았다. 콘텐츠 유형 에 대한 주효과도 유의하게 나타나서 $\left(F_{(3,354)}=4.118, p<.01\right)$, 이에 대해 Bonferroni 사후검정을 실시하였다. 그 결과, 자료 제공과 반 복 학습 $(p<.05)$, 자료 제공과 정보 제공 및 공유 $(p<.05)$ 간에 유의 한 차이를 보였다. 즉, 읽기 중재에 필요한 자료 제공에 대한 앱의 요 구도가 평가 및 모니터링, 반복 학습, 정보 제공 및 공유와 관련된 앱 유형에 비해 유의하게 높았다.

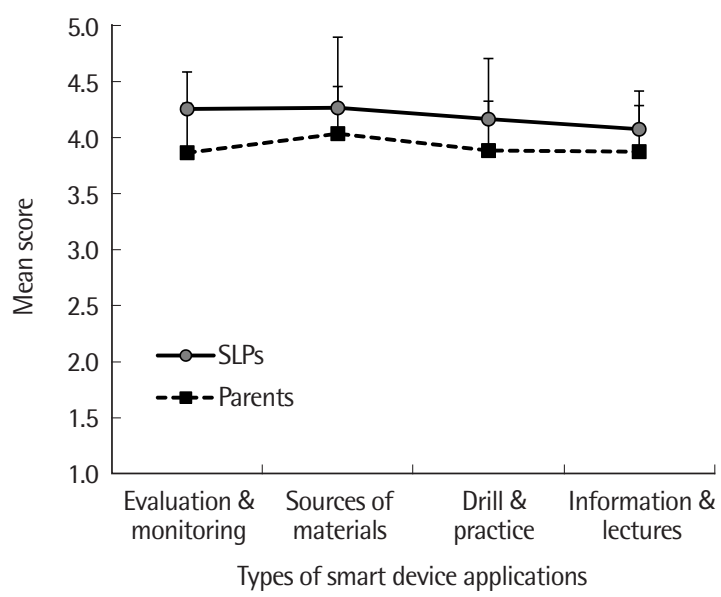

Figure 3. Comparative desire for educational content in smart device applications for children with reading difficulties between speech-language pathologists (SLPS) and parents (five-point scale with a maximum score of 5).

\section{논의 및 결론}

본 연구에서는 장애 아동의 읽기 중재의 실태와 앱 활용 가능성 을 탐색하고 임상 현장과 가정에서 필요로 하는 실제적인 읽기 중 재 앱을 개발하고자 장애 아동의 부모와 언어치료사를 대상으로 장애 아동에 대한 읽기 중재 경험은 어떠한지 알아보고, 읽기 교수 요인(학습환경, 교과내용 및 평가, 교수방법)에 따라서 부모와 언어 치료사 간의 읽기 중재 어려움에 차이가 있는지 살펴보고, 부모와 언어치료사 간에 장애 아동의 읽기 중재에서 필요로 하는 앱 콘텐 츠 유형에 차이가 있는지 조사하였다.

본 연구에서는 언어치료사와 부모 집단 모두에서 장애 아동에게 읽기 중재를 실시한 경험이 있었다. 언어치료사는 음운인식, 어휘, 문장 및 문단 이해하기에 중점을 두고 읽기 중재를 실시하고 있었 다. 이는 언어치료사가 장애 아동의 읽기 이해력에 중점을 두어서 중재를 하고 있다는 Lee (2014)의 연구와 일치한다. 읽기의 속성이 단순한 철자 읽기만으로는 문맥의 의미를 제대로 파악할 수 없으 며, 아동의 어휘 지식, 세상사 지식 등의 부차적인 지식까지 동원되 어야 정확한 의미 파악이 가능해진다. 장애 아동의 경우, 장애 특 성, 부족한 어휘 지식, 의사소통 문제, 인지 처리 과정의 결함 등으 로 인해서 철자 해석 후에 의미를 이해하는 데 더 많은 노력과 시간 이 걸리기 때문에, 언어치료사가 어휘, 문장, 문단 이해와 같은 읽기 이해력에 중점을 두고 있는 것으로 보여진다. 부모는 어휘 이해하 기, 단어 읽기, 한글 철자 익히기에 중점을 두어 읽기 중재를 하는 것으로 나타나서, 부모는 읽기를 학습의 초기 단계부터 관심을 가 지고 가정 내에서 장애 아동의 읽기 중재를 시도하는 특징을 보이 
고 있었다.

언어치료사의 장애 아동의 읽기 중재 경험이 부모보다 유의하게 많았으며, 이는 직업적 특성, 언어재활서비스 제공 대상자의 확대 및 보편화, 읽기 중재에 대한 관심 증대, 부모의 읽기 중재 요구 증가 등의 요인이 작용한 것으로 보여진다. 즉, 바우처 및 교육청 지원사 업 등으로 학령기에도 지속적으로 언어재활서비스를 받는 경우가 늘어나면서, 언어치료사는 장애 아동의 또래 의사소통 능력 증진 뿐만 아니라 학업에 중요한 읽기 중재에 대한 관심도 증대되었다 (Lee, 2014). 또한, 장애 아동의 의사소통 문제가 읽기 발달에 부정 적인 영향을 미친다는 것을 감안한다면, 언어치료사가 장애 아동 의 읽기 문제를 초기에 발견할 수 있어서 취학 전부터 읽기 선수기 술의 중재가 가능한 것도 영향을 미쳤을 것으로 판단된다. 그리고 Lerner (2003)가 제안한 읽기 지도전략을 중심으로 읽기 중재 경험 을 살펴본 결과, 단어재인, 읽기 이해력, 읽기 유창성, 멀티미디어 활 용 순으로 유의하게 낮았다. 즉, 두 집단 모두 장애 아동의 읽기 중 재 시 단어재인에서의 지도전략 경험이 가장 많았으며, 멀티미디어 를 활용하는 지도전략 경험은 가장 적었다. 이러한 결과는 컴퓨터 소프트웨어, 웹을 활용한 멀티미디어 프로그램, 스마트 기기를 활 용한 앱을 사용하는 등의 멀티미디어를 활용한 읽기 중재가 장애 아동에게 효과적이라는 선행연구(Campbell \& Mechling, 2009; Lonigan et al., 2003; Macaruso et al., 2006) 보고가 있지만, 실제 임 상 현장과 가정에서 언어치료사와 부모가 장애 아동의 읽기 중재 에 멀티미디어의 접근과 활용이 쉽지 않다는 것을 시사한다.

언어치료사가 장애 아동의 읽기 중재에 대해서 인식하는 어려움 이 부모에 비해서 유의하게 컸다. 이는 언어치료사는 직업적 특성 으로 다양한 개별장애, 복합장애 아동의 읽기 중재를 해야 하므로, 부모에 비해서 읽기 중재에 대한 어려움이 더 큰 것으로 해석할 수 있다. Park, Pyo, Kim과 Kim (2008)이 특수교사를 대상으로 장애 아동의 국어 교과지도가 어려운 이유를 조사한 결과, 장애의 중도. 중복화와 교육과정의 부적합성, 적절한 교수방법 및 교수자료 부 족, 학급 당 많은 학생 수로 나타났다. Park (2013)이 초등학교 일반 교사의 의사소통장애 및 언어치료에 대한 인식을 조사한 결과, 일 반교사는 학령기 장애 아동이 다른 교과에 비해서 특히 국어 교과 목에 대한 어려움이 크다고 인식하여 이러한 장애 아동을 위한 언 어치료사의 연계 서비스를 요구하고 있었다. 미국 내에서 교사 191 명을 대상으로 읽기 중재 시의 어려움에 대해서 조사한 결과를 살 펴보았을 때, 숙련된 교사도 일반 아동의 다양한 수준의 언어 이해 및 표현 능력으로 인해서 읽기 중재를 실시하는데 어려움이 크다고 하였다(Ganske et al., 2003). 일반 아동보다 장애 아동의 언어 및 읽 기 발달에서의 개인 간 차이가 큰 것을 감안한다면, 언어치료사는
장애 아동의 읽기 목표, 교수방법 및 전략, 교수자료를 구성하고 읽 기 중재를 진행하는데 겪는 어려움이 상당히 크다는 것을 알 수 있 겠다.

교수 요인에 따라 읽기 중재의 어려움에 유의한 차이가 있었으 며, 학습환경보다는 교과내용 및 평가와 교수방법에서 읽기 중재 의 어려움이 유의하게 더 컸다. 언어치료사와 부모 모두 장애 아동 의 읽기 중재를 위한 공간의 조명 및 방음, 학습 장비(예: 컴퓨터, 태 블릿 PC 등), 조직화를 위한 전략(예: 시간표, 수행 체크리스트 등), 보조장비(예: 조이스틱, 마우스 등)와 같은 학습환경의 조정에 대한 어려움은 크지 않았다. 하지만, 다양한 읽기 검사를 사용하여 장애 아동의 읽기 수준을 평가하고 이에 맞는 읽기 자료를 사용하며, 읽 기 수준에 맞추어서 적절한 교수방법을 선택하고 장애 아동의 수 행에 따라 즉각적인 강화를 제공하는 등의 교과내용 및 평가, 교수 방법에 대한 어려움은 큰 것으로 나타났다. Ganske 등(2003)은 일 반교사가 아동의 읽기 중재 시 교과내용 및 평가, 교수방법에서 겪 는 어려움이 크다고 언급하였으며, Park 등(2008)은 장애 유형과 정 도가 다양한 아동, 적절한 교수방법에 대한 교과 내용 및 학습자료 부족, 특수교사의 읽기 중재 관련 지식부족으로 장애 아동의 국어 교과 지도에서 느끼는 부담감이 큰 것으로 보고하였다. 언어치료사 가 지니는 읽기 중재의 어려움을 감소시키기 위해서는 언어치료사 가 장애 아동의 읽기 능력의 평가, 교과내용 구성, 교수방법에 대한 지식과 기술을 지니는 것이 우선시 된다고 할 수 있다. 즉, 읽기 중재 관련 지식과 기술을 잘 갖추기 위해서 전문가를 위한 장애 아동의 읽기 중재 가이드라인 및 지침서 개발, 평가 및 교수방법 특강 및 워 크숍이 필요하며, 언어치료실과 가정에서 모두 사용할 수 있는 장 애 아동용 학습자료가 개발, 배포되어야 할 것이다. 읽기 중재에 대 한 자료를 찾아 장애 아동에게 적용하기가 어려운 현실을 반영하 여, 비공식 평가, 교과내용에 반영될 학습자료 등을 단순한 학습지 형태가 아니라 웹이나 앱의 형태로도 개발하여 언어치료사의 거주 지역과 숙련도에 상관없이 쉽게 접근할 수 있도록 하여 장애 아동 의 읽기 중재로 겪는 어려움을 감소시키고 전문성을 향상시킬 필 요가 있다.

장애 아동의 읽기 중재와 관련된 앱 경험을 조사한 결과, 부모가 언어치료사에 비해서 장애 아동의 읽기 중재를 위해서 앱을 사용 해본 경험이 유의하게 많았다. 부모는 책이나 전문가의 권유를 통 해서 장애 아동의 읽기 중재에 앱을 사용하게 되었으며, 주로 동화 구연, 한글 철자 익히기, 소리와 글자 매칭 등의 앱을 이용하는 것으 로 나타났다. 언어치료사는 전문가의 추천과 책을 통해서 장애 아 동의 읽기 중재에 필요한 앱 정보를 얻고 있었으며, 주로 동화구연, 한글 철자 익히기, 단어 익히기 등의 앱을 이용하는 것으로 나타났 
다. 여기서 주목할 점은 언어치료사보다 부모가 장애 아동의 읽기 중재를 위해서 더 적극적으로 앱을 사용하고 있었다는 것이다. 이 는 부모가 의사소통장애 아동의 의사소통 능력을 증진시키기 위 해서 스마트폰의 앱을 사용하고 있다는 Yim, Kim, Park, Cheon과 Lee (2014)의 연구결과와 일치하는 것으로, 부모가 장애 아동의 삶 의 질 향상과 관련된 의사소통과 읽기 발달을 위해서 앱을 사용하 는데 적극적임을 시사한다. 그리고 소지가 간편하고 이동이 뛰어난 스마트 기기의 특성으로 장애 아동의 부모도 본인이 원하는 콘텐 츠의 앱을 스마트 기기에 설치하고 자유롭게 사용하는 경향이 반 영된 결과로 보여진다. 다른 측면으로는 이러한 결과에 대해서, 언 어치료사는 전문적인 지식과 경험을 바탕으로 장애 아동의 읽기 중재에 필요한 자료를 직접 제작하여 사용할 수 있지만, 부모는 읽 기 자료의 직접 제작보다는 배포된 자료와 앱을 수동적으로 선택 해야 하는 점이 반영된 것으로 해석될 수도 있다.

언어치료사와 부모 집단 모두 장애 아동의 앱 개발에 대한 요구 도가 높게 나타났으며, 언어치료사가 읽기 중재 앱에 대한 요구도가 부모보다 유의하게 높았다. 장애 아동의 읽기 중재를 위한 스마트 기기 앱 콘텐츠를 평가 및 모니터링, 자료 제공, 반복 학습, 정보 제 공 및 공유로 네 가지로 분류하여 살펴보았을 때, 읽기 중재에 필요 한 자료 제공에 대한 앱 콘텐츠에 대한 요구도가 평가 및 모니터링, 반복 학습, 정보 제공 및 공유와 관련된 앱 콘텐츠 유형보다 유의하 게 높았다. 즉, 장애 아동의 읽기 중재에서 다양한 난이도와 주제의 읽기 자료를 제공해주고, 읽기 자료에 대한 이해를 높이기 위한 동 화구연으로 제공하며, 읽기 자료에 해당하는 배경지식을 습득할 수 있도록 음성, 그림, 영상 지원을 하는 형태의 앱에 대한 요구도가 높았던 것이다. Ganske 등(2003)은 읽기 능력이 다양한 아동의 요 구를 충족할 수 있는 읽기 자료 및 관련 자료의 부족이 일반교사의 읽기 중재의 어려움을 가중시킨다고 하였다. Park 등(2008)은 비구 어 아동을 위한 국어과 학습자료 및 교수자료 개발에 대한 특수교 사의 요구도가 높은 점을 지적하면서, 접근이 쉬운 형태의 $\mathrm{CD}$ 나 웹 형태의 읽기 자료 개발이 필요하다고 하였다. 본 연구에서도 언어치 료사와 부모 모두 읽기 중재에서 활용할 수 있는 교과내용을 구성 하는데 어려움이 크다고 나타났는데, 이는 필요로 하는 앱 콘텐츠 는 임상 현장과 가정에서 인식하고 있는 읽기 중재의 어려움과도 관련이 있는 것으로 보여진다. 특히, 언어치료사의 경우, 네 가지로 분류한 앱 콘텐츠 유형의 요구도가 모두 4점('필요하다') 이상으로 나타나서, 읽기 중재에 필요한 다양한 형태의 앱 콘텐츠를 장애 아 동 중재에 활용하고자 하는 요구가 높았다. 따라서 앞으로 장애 아 동의 읽기 중재에서의 전문가 요구를 반영한 스마트 기기 앱을 개 발하여 임상 현장에서 적극적으로 활용될 수 있도록 해야 할 것이
다. 단순히 읽기 중재에 활용될 수 있는 앱의 양적 증가에 초점을 맞 추기 보다는 전문가에 의해서 개발된 질 높은 콘텐츠가 앱으로 개 발될 수 있도록 하는 노력이 필요할 것이다.

본 연구의 결과는 언어치료사와 부모 모두 장애 아동의 읽기 중 재에 대한 경험이 있으며, 읽기와 관련된 교과 과정 및 내용, 교수방 법과 관련하여 어려움을 겪고 있다는 것을 보여준다. 또한, 상당수 의 부모는 장애 아동의 읽기 중재에 앱을 사용한 경험이 있었으며, 언어치료사가 장애 아동의 읽기 중재에 필요한 앱 개발에 대한 요 구도가 부모에 비해서 높다는 것을 알 수 있었다. 향후 임상 현장과 가정에서 장애 아동을 읽기 발달에 필요한 앱을 충분히 활용할 수 있도록 다양한 콘텐츠로 구성된 앱 개발이 필요하며, 본 연구의 요 구도 결과를 토대로 현시점에서는 장애 아동의 읽기 수준에 맞춘 다양한 난이도의 읽기 자료를 제공하고 학습을 촉진하는 데 필요 한 자료 제공형의 읽기 중재 앱 개발이 절실하다. 스마트 기기의 자 체적인 기능을 최대한 활용할 수 있으면서 다양한 장애 유형과 정 도, 읽기 발달의 개인 간 차이를 고려하여 개발될 앱은 개별화된 프 로그래밍이 가능하도록 설계할 필요가 있다. 즉, 전문가가 앱 개발 초기부터 장애 특성과 수행력이 고려될 수 있는 읽기 관련 콘텐츠 를 개발하고 지속적으로 앱 개발자와 논의, 검토하여 앱을 개발해 야 임상 현장과 가정에 보급, 확산이 될 수 있을 것이다. 향후 연구 에서는 장애 유형, 연령대, 장애 정도에 따른 콘텐츠 요구도에 대한 분석을 진행하여, 전반적인 읽기 중재 어려움과 요구도 외에도 사 용자 맞춤형의 앱 개발 가능성에 대해서도 모색할 필요가 있겠다.

\section{REFERENCES}

Ahlgrim-Delzell, L., Browder, D. M., Wood, L., Stanger, C., Preston, A. I., \& Kemp-Inman, A. (2016). Systematic instruction of phonics skills using an iPad for students with developmental disabilities who are AAC users. Journal of Special Education, 50, 86-97.

Baumeister, R. F., Campbell, J. D., Krueger, J. I., \& Vohs, K. D. (2003). Does high self-esteem cause better performance, interpersonal success, happiness, or healthier lifestyles? Psychological Science in the Public Interest, 4 , $1-44$.

Campbell, M. L., \& Mechling, L. C. (2009). Small group computer-assisted instruction with SMART board technology: an investigation of observational and incidental learning of nontarget information. Remedial and Special Education, 30, 47-57.

Chai, Z., Ayres, K. M., \& Vail, C. O. (2016). Using an iPad app to improve phonological awareness skills in young English-language learners with disabili- 
ties. Journal of Special Education Technology, 31, 14-25.

Chai, Z., Vail, C. O., \& Ayres, K. M. (2015). Using an iPad application to promote early literacy development in young children with disabilities. Journal of Special Education, 48, 268-278.

De Leo, G., Gonzales, C. H., Battagiri, P., \& Leroy, G. (2011). A smart-phone application and a companion website for the improvement of the communication skills of children with autism: clinical rationale, technical development and preliminary results. Journal of Medical Systems, 35, 703-711.

Faul, F., Erdfelder, E., Buchner, A., \& Lang, A. G. (2009). Statistical power analyses using $\mathrm{G}^{*}$ Power 3.1: tests for correlation and regression analyses. Behavior Research Methods, 41, 1149-1160.

Ganske, K., Monroe, J. K., \& Strickland, D. S. (2003). Questions teachers ask about struggling readers and writers. The Reading Teacher, 57, 118-128.

Grossen, B. (2003). Six principles for early reading instruction. In W. L. Heward (Ed.), Exceptional children: an introduction to special education (7th ed., pp. 250-252). Upper Saddle River, NJ: Merrill/Prentice Hall.

Jang, Y. J., \& Kim, C. W. (2010). The evolution of smartphone market \& the effect by Android. Communications of the Korean Institute of Information Scientists and Engineers, 28, 48-56.

Je, H. S. (2014). Effect of emergent literacy skills on monosyllable reading of children with typical development and mild intellectual disability (Doctoral dissertation). Ewha Womans University, Seoul, Korea.

Kamhi, A. G., Allen, M. M., \& Catts, H. W. (2001). The role of the speechlanguage pathologist in improving decoding skills. Seminars in Speech and Language, 22, 175-184.

Kang, J. G., Choi, S. K., \& Huh, M. J. (2007). Instructional strategies for students with reading disability: based on case studies. Journal of Speech-Language \& Hearing Disorders, 16, 125-142.

Kim, A. H., Choi, K. S., Jung, H. S., \& Kim, M. J. (2012). A comparison of elementary students with reading disabilities to students without disabilities on word recognition accuracy and speed. Korean Journal of Communication Disorders, 17, 508-519.

Korea Information Society Development Institute. (2011). Analysis of using smart devices. Gwacheon: Author.

Korea Internet \& Security Agency (2015). Survey of using smartphone in 2015. Seoul: Author.

Lee, H. J., Kang, M. K., \& Kim, Y. T. (2013). Current practice and support needs in smart media perceived by the mothers of children with communication difficulties. Communication Sciences \& Disorders, 18, 163-171.

Lee, H. R., \& Lee, S. (2014). Parent survey on the effects of digital instrument on the language development in Korean children. Communication Sciences \& Disorders, 19, 178-190.

Lee, H. S., \& Park, H. S. (1999). A comparison study of phonological processing and word recognition in reading disabled, reading level matched and age matched children. Korean Journal of Communication Disorders, 4, 79102.

Lee, M. K. (2014). Status and perception on reading intervention for students with autism spectrum disorders: focused on speech language pathologists. Journal of Speech-Language \& Hearing Disorders, 23, 113-128.

Lee, Y. (2015). Nonword repetition performance and related factors in schoolaged children with cochlear implants. Journal of Special Children Education, 17, 131-148.

Lee, Y., Lee, S., \& Sung, M. (2015). Analysis of mobile application trends for speech and language therapy of children with disabilities in Korea. Journal of the Korean Society of Speech Sciences, 7, 153-163.

Lee, Y., Yim, D., \& Sim, H. (2012). Phonological processing skills and its relevance to receptive vocabulary development in children with early cochlear implantation. International Journal of Pediatric Otorhinolaryngology, 76, 1755-1760.

Lerner, J. W. (2003). Learning disabilities: theories, diagnosis, and teaching strategies (9th ed.). Boston: Houghton Mifflin.

Lim, J., \& Park, E. (2012). Development and research trends of application as the smart education media for ASD. Journal of the Korean Association for Persons with Autism, 12, 93-117.

Lonigan, C. J., Driscoll, K., Phillips, B. M., Cantor, B. G., Anthony, J. L., \& Goldstein, H. (2003). A computer-assisted instruction phonological sensitivity program for preschool children at-risk for reading problems. Journal of Early Intervention, 25, 248-262.

Macaruso, P., Hook, P. E., \& McCabe, R. (2006). The efficacy of computerbased supplementary phonics programs for advancing reading skills in atrisk elementary students. Journal of Research in Reading, 29, 162-172.

McNulty, M. A. (2003). Dyslexia and the life course. Journal of Learning Disabilities, 36, 363-381.

Park, E., Pyo, Y. H., Kim, J. Y., \& Kim, E. S. (2008). A survey of current status and needs of language arts instruction for students with nonverbal physical disabilities. Korean Journal of Special Education, 42, 143-167.

Park, J. H. (2013). The perception of elementary school teachers about communication disorders and speech and language therapy for school-aged children (Master's thesis). Daegu University, Gyeongsan, Korea.

Plumb, A. M., \& Plexico, L. W. (2013). Autism spectrum disorders: experi- 
ence, training, and confidence levels of school-based speech-language pathologists. Language, Speech, and Hearing Services in Schools, 44, 89-104.

Snow, C. E., Burns, M. S., \& Griffin, P. (1998). Preventing reading difficulties in young children. Washington, DC: National Academy Press.
Yim, D., Kim, S. Y., Park, W., Cheon, S., \& Lee, Y. J. (2014). Analysis on needs based survey of parents and speech-language pathologists for smartphone programs. Communication Sciences \& Disorders, 19, 486-500. 
Appendix 1. 설문 공통문항

\section{IV. 읽기 중재와 관련된 웹, 앱 사용 경험 및 원하는 콘텐츠}

※ 다음은 장애 학생의 읽기 수행력 향상을 위해서 개발되었으면 하는 웹, 앱 콘텐츠의 유형에 대한 필요도를 묻는 문항입니다. 문항을 잘 읽고, 콘텐츠 유형에 대한 필요 도를 표시( $(\sqrt{ })$ 해주시기 바랍니다.

5. 읽기 수행력의 정도, 수준을 평가할 수 있는 콘텐츠

$\square$ 전혀 필요없다

$\square$ 필요없다

$\square$ 보통이다

$\square$ 필요하다

$\square$ 매우 필요하다

6. 정기적으로 읽기 수행력을 평가하여 읽기 발달을 모니터링할 수 있는 콘텐츠

$\square$ 전혀 필요없다

$\square$ 필요없다

$\square$ 보통이다

$\square$ 필요하다

$\square$ 매우 필요하다

7. 장애 학생이 읽기 과제를 하는 동안, 수행(예, 정오 반응)에 대해서 즉각적인 피드백을 제공하는 콘텐츠

$\square$ 전혀 필요없다

$\square$ 필요없다

$\square$ 보통이다

$\square$ 필요하다

$\square$ 매우 필요하다

8. 다양한 난이도와 주제의 읽기 자료를 제공하는 콘텐츠

$\square$ 전혀 필요없다

$\square$ 필요없다

$\square$ 보통이다

$\square$ 필요하다

$\square$ 매우 필요하다

9. 다양한 난이도와 주제의 구연 동화를 제공하는 콘텐츠

$\square$ 전혀 필요없다

$\square$ 필요없다

$\square$ 보통이다

$\square$ 필요하다

$\square$ 매우 필요하다

10. 읽기 자료와 관련된 배경지식을 음성, 그림, 영상으로 제공하는 콘텐츠

$\square$ 전혀 필요없다

$\square$ 필요없다

$\square$ 보통이다

$\square$ 필요하다

$\square$ 매우 필요하다

11. 한글 철자를 익힐 수 있는 콘텐츠
$\square$ 전혀 필요없다
$\square$ 필요없다
$\square$ 보통이다
$\square$ 필요하다
$\square$ 매우 필요하다

12. 생활 관련 로고, 상징, 그림들을 제공하는 콘텐츠
$\square$ 전혀 필요없다
$\square$ 필요없다
$\square$ 보통이다
$\square$ 필요하다
$\square$ 매우 필요하다 


\section{국문초록}

\section{읽기 중재 어플리케이션 개발을 위한 장애 아동의 읽기 중재 실태 및 부모, 언어치료사의 요구 분석} 이영미 ${ }^{1} \cdot$ 김영태 $^{2} \cdot$ 박은혜 ${ }^{3}$

1동명대학교 언어치료학과, ${ }^{2}$ 이화여자대학교 언어병리학과, ${ }^{3}$ 이화여자대학교 특수교육학과

배경 및 목적: 본 연구는 언어치료사와 부모의 장애 아동에 대한 읽기 중재 경험과 어려움에 대해서 살펴보고, 읽기 능력 증진을 위해 서 필요한 스마트 기기의 어플리케이션(이하 앱)의 콘텐츠의 요구도를 조사하고자 하였다. 방법: 읽기 중재 경험, 중재 어려움, 앱 요구도, 배경 정보를 묻는 문항을 개발하였다. 전국에 소재한 기관의 언어치료사와 장애 아동의 부모에게 온라인 설문조사를 실시하여, 총 120 부(언어치료사용 60 부, 부모용 60 부)의 설문지를 분석하였다. 결과: 언어치료사가 부모에 비해서 유의하게 많은 읽기 중재 경험을 가지 고 있었으며, 읽기 이해력에 초점을 두어서 중재를 하고 있는 것으로 나타났다. 언어치료사가 부모에 비해서 읽기 중재의 어려움을 유의 하게 높게 인식하고 있었으며, 읽기 교과 내용 및 평가, 교수방법에 대한 어려움이 큰 것으로 나타났다. 그리고 언어치료사가 부모보다 읽기 중재 앱에 대한 요구도가 유의하게 높았으며, 읽기 자료를 제공해주는 앱에 대한 요구도가 평가 및 모니터링, 반복 학습, 정보 제공 과 관련된 앱보다 유의하게 높았다. 논의 및 결론: 본 연구에서는 언어치료사와 부모의 장애 아동에 대한 읽기 중재 실태와 요구를 분 석함으로써 스마트 기기의 어플리케이션을 개발하여 임상과 가정에서 사용할 수 있는 읽기 중재 앱을 개발하는 데 필요한 기초 자료를 제시하고 장애 아동의 읽기 중재에 적극적인 지원 가능성을 모색하게 하였다.

핵심어: 읽기 중재, 아동, 언어치료사, 부모, 요구 조사, 읽기 중재용 어플리케이션

본 연구는 2015년 대한민국 교육부와 한국연구재단의 지원을 받아수행된 연구임(NRF-2015S1A5A2A03049681).

\section{참고문헌}

강종구, 최성규, 허명진(2007). 읽기장애 아동들을 위한 지도 전략: 사례연구들을 중심으로. 언어치료연구, 16, 125-142.

김애화, 최경순, 정현승, 김민정(2012). 일반학생과 읽기장애학생의 단어인지 정확도 및 속도 특성 연구. 언어청각장애연구, 17, 508-519.

박은혜, 표윤희, 김정연, 김은숙(2008). 비구어 지체장애 학생을 위한 국어과 교수-학습 지도의 실태 및 요구분석. 특수교육학연구, 42, 143-167.

박진희(2013). 학령기 의사소통장애 및 언어치료에 대한 초등학교 교사들의 인식. 대구대학교대학원 석사학위논문.

이미경(2014). 자폐스펙트럼장애 학생의 읽기 중재 실태 및 인식: 언어재활사를 중심으로. 언어치료연구, 23, 113-128.

이영미(2015). 학령기 인공와우 아동의 비단어 따라말하기 수행력과 관련 요인 분석. 특수아동교육연구, 17, 131-148.

이영미, 이수복, 성민경(2015). 국내 장애 아동을 위한 언어치료용 모바일 어플리케이션 현황 분석. 말소리와음성과학, 7, 153-163.

이현정, 강민경, 김영태(2013). 어머니가 인식한 자녀의 의사소통 어려움과 스마트미디어 활용 현황 및 요구조사. 언어청각장애연구, 18, 163-171.

이혜숙, 박현숙(1999). 읽기장애 아동과 비장애 아동의 음운처리과정 및 읽기재인간 비교 연구. 언어청각장애연구, 4, 79-102.

이희란, 이승복(2014). 아동의 디지털 기기 사용과 언어발달에 관한 부모의 인식 조사. 언어청각장애연구, 19, 178-190.

임동선, 김신영, 박원정, 천성혜, 이여진(2014). 스마트폰 프로그램 개발을 위한 의사소통장애 아동 부모 및 전문가 요구 분석. 언어청각장애연구, 19 ,

486-500.

임장현, 박은혜(2012). ASD인을 위한 스마트 교육 미디어로서의 앱 개발 및 연구현황 분석. 자폐성장애연구, 12, 93-117.

장윤정, 김철우(2010). 스마트폰 시장의 진화와안드로이드의 영향. 정보과학회지, 28, 48-56.

정보통신정책연구원(2011). 스마트 기기 이용행태 실증분석. 과천: 정보통신정책연구원.

제현순(2014). 초기 문해력 기술들이 일반 아동 및 지적장애아동의 1 음절 읽기 능력에 미치는 영향. 이화여자대학교대학원 박사학위논문.

한국인터넷진흥원(2015). 2015년 모바일 인터넷 이용 실태조사. 서울: 한국인터넷진흥원. 